\title{
Review Article \\ Obstructive Sleep Apnoea Syndrome and Weight Loss: Review
}

\author{
Douglas C. Cowan ${ }^{1}$ and Eric Livingston ${ }^{2}$ \\ ${ }^{1}$ Sleep Department, Gartnavel General Hospital, Glasgow G12 0YN, UK \\ ${ }^{2}$ Respiratory Department, Glasgow Royal Infirmary, 16 Alexandra Parade, Glasgow G31 2ER, UK
}

Correspondence should be addressed to Eric Livingston, eric.livingston@ggc.scot.nhs.uk

Received 9 November 2011; Accepted 9 January 2012

Academic Editor: Sophia Schiza

Copyright (C) 2012 D. C. Cowan and E. Livingston. This is an open access article distributed under the Creative Commons Attribution License, which permits unrestricted use, distribution, and reproduction in any medium, provided the original work is properly cited.

\begin{abstract}
Obstructive sleep apnoea (OSA) syndrome is common, and obesity is a major risk factor. Increased peripharyngeal and central adiposity result in increased pharyngeal collapsibility, through increased mechanical loading around the upper airway, reduced tracheal traction on the pharynx, and reduced neuromuscular activity, particularly during sleep. Significant and sustained weight loss, if achieved, is likely to be a useful therapeutic option in the management of OSA and may be attempted by behavioural, pharmacological, and surgical approaches. Behavioural therapy programs that focus on aspects such as dietary intervention, exercise prescription patients and general lifestyle counselling have been tested. Bariatric surgery is an option in the severely obese when nonsurgical measures have failed, and laparoscopic adjustable gastric banding and Roux-en-Y gastric bypass are the most commonly employed techniques in the United Kingdom. Most evidence for efficacy of surgery comes from cohort studies. The role of sibutramine in OSA in the obese patients has been investigated, however, there are concerns regarding associated cardiovascular risk. In this paper the links between obesity and OSA are discussed, and the recent studies evaluating the behavioural, pharmacological and surgical approaches to weight loss in OSA are reviewed.
\end{abstract}

\section{Introduction}

Obstructive sleep apnoea (OSA) syndrome is common with a prevalence of approximately $4 \%$ in middle-aged men and $2 \%$ in middle-aged women [1]. Frequent partial (hypopnoea) or complete (apnoea) closure of the upper airway during sleep leads to oxygen desaturation, increased respiratory effort, arousal, and sleep fragmentation. Patients typically present with witnessed apnoeas, loud intermittent snoring, and excessive daytime somnolence [2]. The syndrome is associated with impairment in quality of life [3], cognitive functioning, and work performance [4], and with an increased risk of road-traffic accidents [5]. OSA is considered an independent risk factor for hypertension $[6,7]$ and has associations with coronary artery disease [8], stroke [9], heart failure [10], arrhythmias [11], metabolic syndrome [12], and type 2 diabetes [13]. Obesity is an important risk factor for the development of OSA [14-16] and is unique amongst the major risk factors in being modifiable [17]. There is a wealth of studies evaluating the effects of weight loss, achieved by behavioural, pharmacological, and surgical approaches, in the management of OSA in the obese patients. In this review, we will discuss the links between excess body weight and development of OSA and the different methods of achieving weight loss and their effectiveness.

\section{Obesity as a Risk Factor for OSA}

The evidence to support the role of excess weight as a causal factor in the aetiology of OSA is convincing. In a population study involving 2148, prevalence of obesity was significantly higher in those with OSA than those without, whether male $(22 \%$ versus $8 \%)$ or female (32\% versus $18 \%)$ [18]. Another study of 161 obese patients (BMI $\geq 30 \mathrm{~kg} / \mathrm{m}^{2}$ ) showed that OSA was present in over 50\%, and in $25 \%$ this was severe [19]. Amongst the morbidly obese patients $\left(\mathrm{BMI} \geq 40 \mathrm{~kg} / \mathrm{m}^{2}\right)$, prevalence of OSA as high as $98 \%$ has been reported [20]. Using data from the population-based Wisconsin Sleep Cohort Study [1], Young et al. estimated that, in $41 \%$ of adults with mild or worse sleep disordered breathing (SDB) (AHI $\geq 5$ ) and in 58\% of those with moderate or worse SDB (AHI $\geq 15$ ), sleep disordered 
breathing (SDB) was attributable to excess weight (defined as BMI $\geq 25 \mathrm{~kg} / \mathrm{m}^{2}$ ) [16]. In a study based on data from the 2005 National Sleep Foundation Sleep in America poll, 59\% of 379 obese individuals were at high risk for OSA as defined by the Berlin Questionnaire [21]. In the Sleep Heart Health Study based on 5615 adults, the odds ratio for an AHI of 15 or greater with a BMI difference of $10 \mathrm{~kg} / \mathrm{m}^{2}$ was 2.4 [22]. A longitudinal population-based study of 690 adults followed up at 4 years demonstrated that a $10 \%$ weight gain predicted a $32 \%$ (95\% confidence interval (CI) 20-45\%) increase in AHI while a $10 \%$ weight loss predicted a $26 \%$ (95\% CI $18-34 \%$ ) decrease in AHI. Further, a 10\% increase in weight predicted a 6 -fold (95\% CI 2.2-17.0) increase in the odds of developing moderate-to-severe SDB [23]. The Sleep Heart Health Study similarly confirmed progression and regression of sleep-disordered breathing (as quantified by respiratory disturbance index (RDI)) with weight gain and loss but also demonstrated that the association was stronger for males than for females [24]. Several studies have confirmed obesity and BMI $[22,25,26]$ as predictors of OSA. Likewise, other relevant anthropometric measures have been associated with OSA such as neck circumference [22, 26-28], waist circumference [29], waist-hip-ratio [25], and visceral adiposity $[30,31]$.

\section{Mechanisms for the Development of OSA in the Obese Patients}

There are several mechanisms by which obesity could result in OSA, and these may act synergistically. It is proposed that increased peripharyngeal fat deposition results in mechanical loading that offsets the maintenance of airway patency by the dilator muscles and that this increase in collapsibility is particularly prominent during sleep when there is a reduction in neuromuscular activity [32-34]. In addition, there is some evidence to suggest that central obesity in particular may have detrimental effects on neuromuscular activity in the upper airway [35]. Obesity is associated with a reduction in functional residual capacity (FRC) [36]. Pharyngeal collapsibility may be further accentuated by this reduction in FRC and subsequent decrease in tracheal traction on the pharynx [34]. Finally, a self-perpetuating cycle may develop in which sleep disruption leads to increased appetite (especially for calorie-rich high-carbohydrate foods) [37], reduced activity levels, further weight gain, and increased severity of OSA [38].

\section{Weight Loss as a Therapeutic Approach in OSA}

4.1. Behavioural Methods (See Table 1). Several studies have been performed to evaluate the effects of approaches including dietary modification and exercise, as well as counselling. Two small cohort studies $[39,40]$ and a larger randomised, controlled, parallel study [41] have assessed the effects of a very low-calorie diet (VLCD) given over two to three months. In each of these studies, significant improvements in weight and BMI occurred. Johansson et al. [41] reported a significant reduction in AHI with 17\% "cured," while, in the study of Kansanen et al. [40], RDI was significantly decreased with "cure" in 20\%. All three studies demonstrated improvements in nocturnal oxygenation, and a reduction in daytime somnolence was reported by two $[39,41]$. In a follow-on study [42], Johansson et al. enrolled patients, on the completion of the VLCD, into a weight-loss maintenance programme incorporating behaviour modification group therapy focusing on elements such as nutrition education and increased physical activity. After one year, anthropometric measures and sleep variables had increased compared to post-VLCD values but were still significantly better than at baseline, with "cure" in $10 \%$. In another study, patients with mild-to-moderate OSA were randomised to CPAP, an oral appliance or conservative measures (sleep hygiene), and overweight individuals (BMI $\geq 23 \mathrm{~kg} / \mathrm{m}^{2}$ ) were invited to attend a weight control programme in the local Dietetics Unit [43]. Weight loss occurred in 45 participants across the three treatment groups after 10 weeks $(75.8$ (1.6) $\mathrm{kg}$ to 72.5 $(1.5) \mathrm{kg}$ ), and this was accompanied by a decrease in AHI (24.6 (1.7) to 19.1 (2.0)). 8 participants were cured $(\mathrm{AHI}<5)$ with a mean weight loss of $2.9(1.0) \mathrm{kg}$. In addition, there was a linear relationship between change in $\mathrm{AHI}$ and body weight $(r=0.298, P=0.004)$ independent of treatment modality. Kemppainen et al. performed a prospective, and randomised, controlled parallel study comparing a VLCD and supervised lifestyle intervention with routine lifestyle counselling over 3 months [44]. BMI decreased by $5.4 \mathrm{~kg} / \mathrm{m}^{2}$ in the intervention group compared to only $0.49 \mathrm{~kg} / \mathrm{m}^{2}$ in the control group $(P<0.001)$. The reduction in AHI was not significantly different between groups, however (intervention group: 3.2 events/hour, control group: 1.3 events/hour). Likewise, a small cohort study in which patients completed a 16-week program including VLCD and an exercise program showed significant weight loss and reduction in daytime sleepiness but no significant change in AHI after 16 weeks [45]. In this study, at one year, patients had again regained weight although weight was still significantly less than at baseline. In a randomised and controlled, parallel study, Tuomilehto et al. reported improvements following a VLCD for 12 weeks with supervised lifestyle counselling focussing on diet, exercise and lifestyle modification [46]. After one-year significant improvements were seen in AHI, number of patients cured, nocturnal oxygenation, weight, and BMI in the intervention group. Nerfeldt et al. [47] have recently reported the results of a 2-year weight reduction program that included an 8 -week low-calorie diet and behavioural change support. Disappointingly, no change in AHI was found; however, there were significant reductions in BMI, ODI, arousal index, and ESS. Promising results have been reported for a program including formal cognitive behavioural therapy [48] and one including a 6-month exercise training program [49].

Thus, the outcomes of behavioural therapy for weight loss in OSA are mixed. Furthermore, for these programmes to be available in the clinical setting may not be economically feasible due to the costs involved such as employment of dietician, physiotherapist, and nurse. Moreover, drop-out rate is not insubstantial; in the study by Nerfeldt et al. 


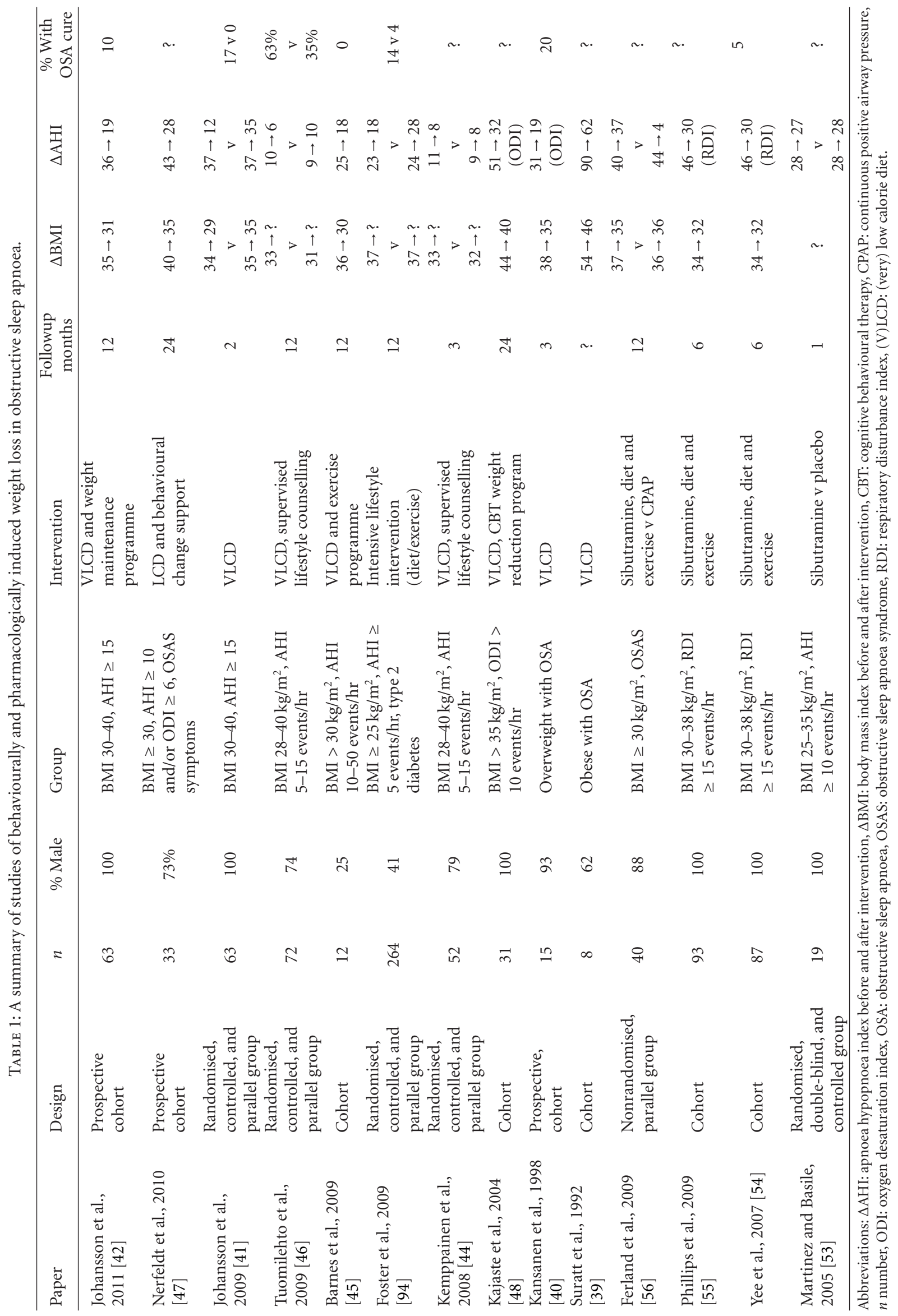


$30 \%$ of patients did not complete the two-year program [47]. Maintenance of the weight loss achieved is variable particularly if long-term followup is not provided [50]. For lifestyle changes such as integration of regular exercise into the routine to be sustained is heavily dependent on individual motivation [51].

4.2. Pharmacological Methods (See Table 1). Sibutramine is a serotonin and noradrenaline reuptake inhibitor that promotes weight loss by enhancing satiety and increasing energy expenditure through thermogenesis [52]. A randomised, placebo controlled trial of sibutramine, given to overweight males with OSAHS, found no change in AHI or weight over one month [53]. More recently, the results of a cohort study, in which obese males with OSAS were enrolled into a 6-month sibutramine-assisted weight loss program incorporating a dietary prescription and advice on exercise, have been reported $[54,55]$. Significant improvements were seen in weight $(-8.3 \pm 4.7 \mathrm{~kg})$, RDI $(-16.3 \pm 19.4$ events $/ \mathrm{hr})$, and ESS $(-4.5 \pm 4.6)$, and $4 / 87$ (5\%) were "cured" with RDI $<5$ events/hr by 6 months [54]. Significant, though modest, improvements in insulin sensitivity and lipid profile were also reported [55]. In a further study, sibutramineassisted weight loss was compared with conventional CPAP treatment and lifestyle recommendations over one year in a nonrandomised, parallel study in obese patients with OSAS [56]. Weight decreased by $5 \mathrm{~kg}$ in the sibutramine treated group while remaining unchanged in the CPAP group. Sibutramine treatment was associated with no change in AHI or in ESS but an improvement in mean nocturnal oxygen saturations and also an improvement in sleep architecture. CPAP on the other hand significantly improved both AHI and ESS, led to greater improvement in sleep architecture, and led to improvements in other sleep and respiratory variables. Overall, sibutramine-assisted weight loss was concluded to be inferior to CPAP. More recently, in January 2010, the marketing authorisation for sibutramine has been suspended by the Medicines and Healthcare products Regulatory Agency due to concerns that cardiovascular risks outweighed benefits and that there may be an increased risk of nonfatal myocardial infarction and stroke $[57,58]$. Orlistat is another therapeutic option for management of weight loss and this agent inhibits gastrointestinal lipase thus reducing fat absorption [59]. To the authors' knowledge no trial has evaluated the use of orlistat in management of obese sleep apnoea patients.

4.3. Surgical Methods (See Table 2). The National Institute for Health and Clinical Excellence Guidelines state that bariatric surgery should be recommended as a treatment option for adults with BMI of $40 \mathrm{~kg} / \mathrm{m}^{2}$ or more, or between 35 and $39.9 \mathrm{~kg} / \mathrm{m}^{2}$ in the presence of significant comorbidities such as type 2 diabetes or hypertension. In addition, all nonsurgical measures should have been employed with failure to achieve or maintain adequate weight loss over at least 6 months. Further, individuals should be managed within a specialist obesity service, be both fit for anaesthesia and surgery, and willing to commit to long-term followup
[57]. There are several surgical procedures that can be performed including laparoscopic adjustable gastric banding (LAGB), Roux-en-Y gastric bypass (RYGB), laparoscopic sleeve gastrectomy (LSG), and laparoscopic biliopancreatic diversion. Of these, the LAGB and RYGB are more commonly available in the UK [60]. The mechanisms by which bariatric procedures lead to weight reduction incorporate gastric restriction and/or malabsorption and can be summarised as the BRAVE effects: bile flow alteration, restriction of gastric size, anatomical gut rearrangement and altered flow of nutrients, vagal manipulation, and enteric gut hormone modulation [61]. The LAGB procedure entails placement of a band around the proximal stomach forming a pouch with a narrow outlet just distal to the gastrooesophageal junction. The degree of restriction can be altered by inflating or deflating a balloon within the band with saline via a subcutaneous port $[62,63]$. In RYGB surgery, the proximal stomach is transected forming a small gastric pouch which is joined to the roux limb of jejunum with the result that the more distal stomach, the complete duodenum, and proximal jejunum are bypassed [62].

Since the 1980's, the results of several studies of the effects of surgical weight loss in patients with OSA have been published (see Table 2). To the authors' knowledge, with the exception of one [64], these have all been cohort studies either of obese individuals [65-68], specifically those with OSA $[63,69-80]$ or, in one case, those with respiratory comorbidity (chronic obstructive pulmonary disease, OSA, or obesity hypoventilation syndrome) requiring noninvasive positive pressure ventilation [81]. In all studies, where measured, a significant improvement in AHI occurred after surgery, in addition to the expected reduction in BMI. Furthermore, resolution of OSA occurred in up to $80 \%$ [72] however, this was variable; in the study of Lankford et al. [70], "cure" did not occur in any patient. Postoperative evaluation was carried out between 3 [72] and 28 months [71]. Other benefits have also been reported. An improvement in nocturnal oxygenation is seen with reduced oxygen desaturation index $[63,79]$ and time with saturation less than $90 \%[79,81]$, increase in minimum oxygen saturation $[63,66,69,71,73,74,78,79]$ and mean oxygen saturation $[63,71,78,79]$. Daytime hypoxaemia $[80,81]$ and hypercapnia [81], too, are improved. Sleep efficiency is increased $[63,69,74,77]$ and sleep architecture enhanced with decreases in stages 1 [76] and 2 [76, 77], increases in stages $3[63,75-77,82]$ and 4 [75-77, 82], reduced REM latency $[69,74,77]$, and increased REM sleep $[63,75-77,82]$. CPAP use $[69,73,75,78,81]$ and CPAP pressure requirements $[69-71,73]$ are less. Likewise, there is a reduction in daytime sleepiness (ESS) [69, 73-75, 80, 83], snoring $[63,83]$, witnessed apnoeas [83], and other OSArelated symptoms [83] and improvement in both quality of life and depression scores [75]. One study demonstrates that spirometric measures increase significantly one year after surgery [81], and similar results were reported 6 months after intragastric balloon insertion in another study [80]. Finally, reduction in glucose, HbAlc, triglycerides, and insulin with increase in HDL have been reported with an overall reduction in metabolic syndrome [75]. 


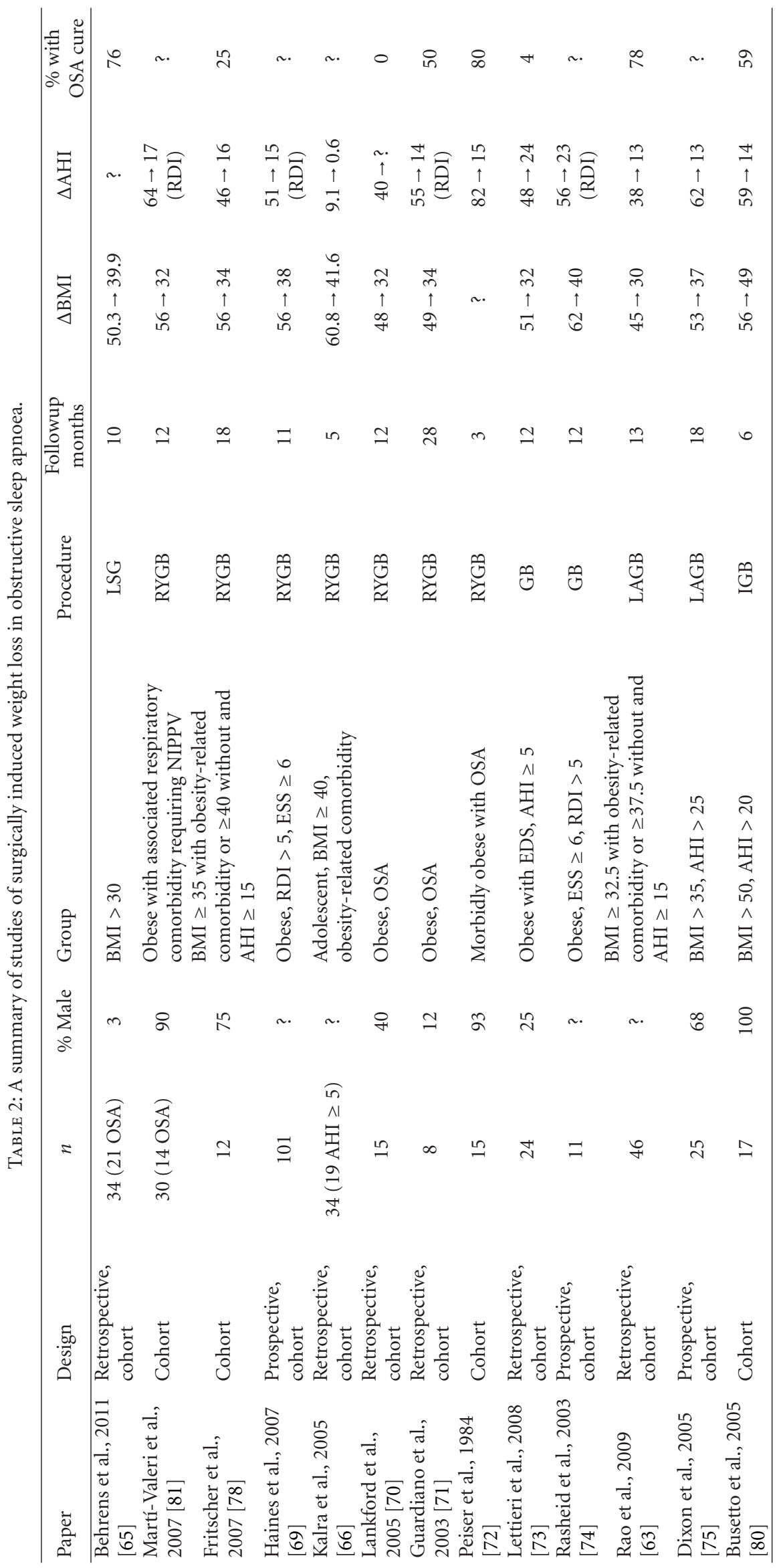




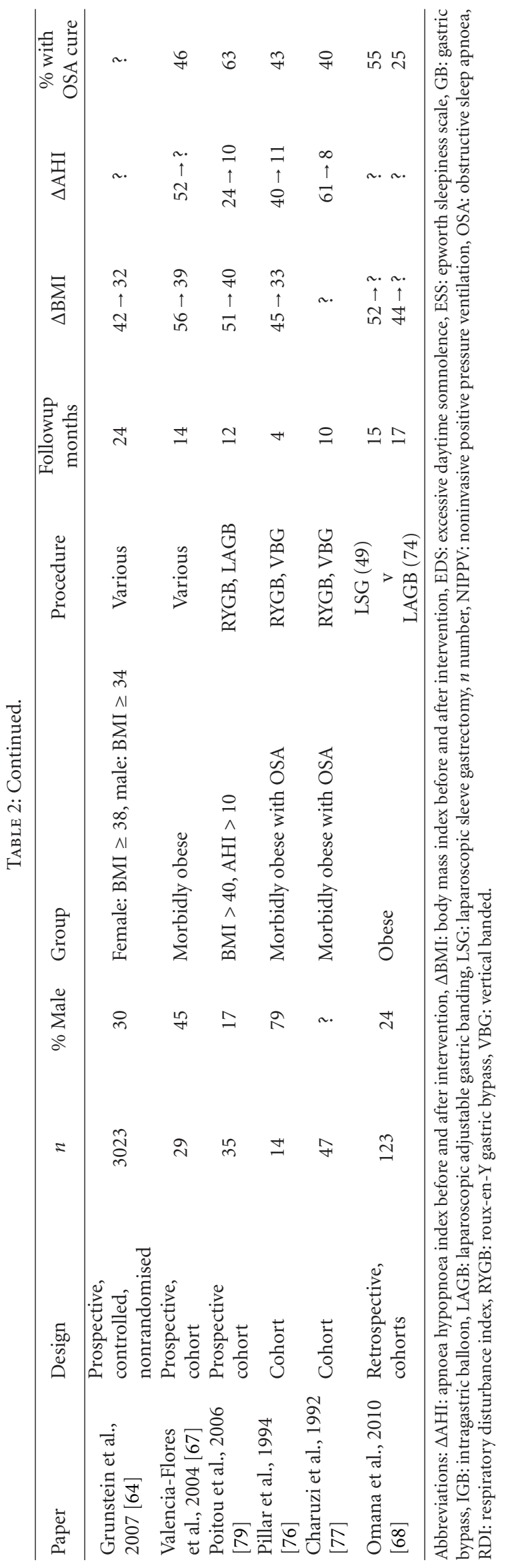


From these reports, it is tempting to conclude that surgical weight loss is the panacea for OSA at least in the obese population. Caution is required in the interpretation of these studies, however, the main criticisms being that they did not include a control group, and in many cases data collection was retrospectively carried out. A large multicentre prospective controlled study with 2-year followup was carried out in Sweden by Grunstein et al. [64]. For ethical reasons, participants were not randomised and the study was questionnaire based. 1592 obese individuals undergoing various bariatric procedures were compared with 1431 matched controls that were provided with routine obesity management including dietary advice, physical training, lowcalorie diets and behaviour modification. The odds ratios for development of new symptoms of apnoea, snoring, and daytime sleepiness were $0.28,0.18$, and 0.66 , respectively, for the surgical group compared to the control group. Likewise, persistence of these symptoms was markedly lessened in the surgical group (approximately 20-30\%) compared to controls (approximately 50-70\%). Thus, surgery was associated with a marked reduction in OSA-related symptoms. Unfortunately no attempt was made to objectively measure sleep disordered breathing in this study at baseline or followup.

In summary, the aforementioned studies report promising results regarding the effects of bariatric surgery on sleep apnoea symptoms and polysomnography at least in the short term up to one to two years. What of the long term are benefits maintained? One study of LAGB surgery for obesity showed progressive loss of weight over the first 2 to 3 years with a plateau in BMI to 6 years [83], similar results being found in another study of 157 obese patients over a 5year period [84]. This finding is at odds with the results of another study in which significant weight gain was found over a 10-year period following RYGB surgery, the increase being more in the super-obese (BMI $\left.\geq 50 \mathrm{~kg} / \mathrm{m}^{2}\right)$ than in the morbidly obese $\left(\mathrm{BMI}<50 \mathrm{~kg} / \mathrm{m}^{2}\right)$ [85]. In a study of 14 obese subjects with OSA, BMI decreased significantly from baseline $\left(45 \mathrm{~kg} / \mathrm{m}^{2}\right)$ to 4.5 months postop $\left(33 \mathrm{~kg} / \mathrm{m}^{2}\right)$ and increased only insignificantly $\left(35 \mathrm{~kg} / \mathrm{m}^{2}\right)$ at 7.5 years. However, while AHI decreased significantly from $40 / \mathrm{hr}$ to $11 / \mathrm{hr}$ at 4.5 months a twofold increase to $24 / \mathrm{hr}$ occurred at 7.5 years, the change in AHI at 7.5 years was independent of change in BMI [76]. Another older study documented substantial weight gain and relapse of OSA in a small subgroup of obese sleep apnoea patients for which data was available at 7 years [77]. Thus, the results are conflicting but overall would suggest that weight loss is not maintained and that OSA may relapse in the years following surgery, perhaps due to factors other than just weight gain.

The morbidity and mortality related to surgical intervention should also be considered in the overall evaluation of the benefits of bariatric surgery. Grunstein et al. reported a perioperative mortality rate of $0.21 \%$ and an incidence of other complications (including bleeding, thromboembolism, wound complications, deep infections, pulmonary, and other complications) of 13\% [64]. Omana et al. reported no mortalities or major complications and a rate of $15 \%$ for minor complications for LABG in 74 subjects [68]. Complications specific to LAGB surgery include band slippage or erosion, pouch enlargement, oesophageal dilatation, and oesophageal or gastric perforation while those for RYGB include staple line disruption and leak, stricture, small bowel obstruction and hernia (both internal and incisional) [86]. A large metaanalysis of mortality after bariatric surgery reported up to 30 -day mortality of $0.28 \%$ and $>30$-day to 2 -year mortality of $0.35 \%$ [87]. Concerns have been raised over the use of risk of bowel distension and subsequent anastomotic leak in association with the use of bilevel positive airway pressure in the immediate postop period after gastric bypass; however, this seems rare complication [88].

\section{Mechanisms for the Resolution of OSA after Weight Loss}

The mechanisms by which weight loss results in a reduction in severity of OSA or even resolution have been explored in a number of studies. Following weight loss, there is a reduction in nasopharyngeal collapsibility and resistance implying that the calibre of the upper airway increases [39, 89]. In the study of Busetto et al. discussed earlier, acoustic pharyngometry was utilised to measure pharyngeal crosssectional area [80]. At baseline, pharyngeal cross-sectional areas were significantly reduced in obese individuals with OSAS compared to nonobese controls. Six months after intragastric balloon insertion, weight loss was associated with significant increases in cross sectional area at the oropharyngeal junction both upright and supine and the mean pharyngeal cross-sectional upright. However, mean pharyngeal cross-sectional area and crosssectional area at the glottis level were still significantly lower than for nonobese controls. Pharyngeal and glottic function appears to be improved [90]. The level to which the upper airway critical pressure (i.e., the nasal pressure below which inspiratory airflow ceases) falls following weight loss determines whether there is complete resolution of OSA or not [91]. The improvements seen in pharyngeal function may be related to reductions in mechanical loading particularly due to parapharyngeal fat pads. One study using CT imaging showed that velopharyngeal volume and lateral diameter are increased while facial and abdominal fat volumes decrease along with parapharyngeal fat pad volume [17]. In this study, reduction in upper airway length and in visceral abdominal fat best explained improvement in AHI after weight loss $\left(R^{2} 0.31, P=0.004\right)$, and, interestingly, changes in parapharyngeal fat did not correlate with changes in AHI. An alternative explanation is that reduction in central adiposity and the resulting reduction in production of adipokines that act on the central nervous system may lead to enhanced neuromuscular control of pharyngeal calibre [35]. Weight loss is associated with significant improvement in vital capacity, total lung volume, functional residual capacity, and forced expiratory volume [92], and this increase in lung volumes may result in increased tracheal traction on the pharynx. In the study discussed earlier by Kemppainen et al., no significant differences were found in nasal resistance or nasal volume after successful weight loss indicating that 
the improvement in OSA is not related to changes in nasal airflow [44]. Absence of attenuation of OSA after weight loss may be related to presence of concomitant otorhinolaryngoiatric pathology [93].

\section{Conclusion}

Obesity is a major (and perhaps the leading) risk factor for obstructive sleep apnoea. The prevalence of OSA is increased in the obese patients and vice versa; OSA is related to various anthropometric measures; the severity of OSA increases in association with weight increase. Pathophysiological mechanisms by which obesity can lead to OSA have been identified. It follows that weight loss may lead to an improvement in the severity of OSA and perhaps even it's resolution. This has been borne out in studies evaluating behavioural and surgical approaches to weight loss. Behavioural methods have focussed on dietary intervention, encouragement of exercise, and support in lifestyle change, and randomised studies have been encouraging. The evidence for benefits in association with bariatric surgery stems from cohort studies, many of them retrospective, but nonetheless persuasive. However, surgical intervention is recommended only after nonsurgical measures have failed and is associated with an albeit low mortality rate and also significant morbidity.

Although the studies of both behavioural and surgical interventions aimed at weight loss in the management of OSA have shown promising results, there are some limitations to these studies that should be noted. The majority of studies reviewed were uncontrolled and involved low subject numbers often with a male predominance. There were varying criteria for inclusion in studies with respect to the severity of obesity and both the presence and severity of OSA; the inclusion criteria for some studies included the presence of excessive daytime somnolence or other obesityrelated comorbidities while other studies did not. Likewise, different methodologies were utilised for the confirmation of OSA such as polysomnography, limited sleep studies, and respiratory polygraphy, and there was variation in the outcome measures reported such as apnoea hypopnoea index, respiratory disturbance index, oxygen desaturation index, and other measures of nocturnal oxygenation. For these reasons, it is difficult to compare the different studies and to extrapolate to the wider population. The proportion of subjects lost to followup was often significant and this may lead to bias with overestimation of the improvement associated with the intervention as those not benefitting are more likely not to return for reassessment. The time to reevaluation varied from as little as 2 months to over 24 months. The benefits reported in studies with shorter durations may have been influenced by short-term simultaneous behavioural changes such as reduction of alcohol intake or increase in exercise which may not be maintained in the longer time. Alternatively shorter studies may have underestimated the potential for weight loss and attendant improvements in OSA that may be possible with longer behavioural interventions.

For either approach, behavioural or surgical, to be successful, weight loss has to be maintained in the long term to prevent relapse, and "maintenance of weight loss programmes" necessarily incorporating similar features to the behavioural weight loss programmes may not be economically feasible. Furthermore, success of such programmes or of maintenance of weight loss independently is heavily dependent on the motivation of the individual. Further randomised, controlled trials are required to confirm the beneficial effects of bariatric surgery, and those of the behavioural interventions. Studies are necessary to identify those in which behavioural therapy is likely to be effective so that limited resources are efficiently utilised.

\section{References}

[1] T. Young, M. Palta, J. Dempsey, J. Skatrud, S. Weber, and S. Badr, "The occurrence of sleep-disordered breathing among middle-aged adults," The New England Journal of Medicine, vol. 328, no. 17, pp. 1230-1235, 1993.

[2] W. T. McNicholas, "Diagnosis of obstructive sleep apnea in adults," Proceedings of the American Thoracic Society, vol. 5, no. 2, pp. 154-160, 2008.

[3] Y. Lacasse, C. Godbout, and F. Sériès, "Health-related quality of life in obstructive sleep apnoea," European Respiratory Journal, vol. 19, no. 3, pp. 499-503, 2002.

[4] H. M. Engleman and N. J. Douglas, "Sleep - 4: sleepiness, cognitive function, and quality of life in obstructive apnoea/hypopnoea syndrome," Thorax, vol. 59, no. 7, pp. 618622, 2004.

[5] J. Terán-Santos, A. Jiménez-Gómez, and J. Cordero-Guevara, "The association between sleep apnea and the risk of traffic accidents," The New England Journal of Medicine, vol. 340, no. 11, pp. 847-851, 1999.

[6] G. V. Robinson, J. R. Stradling, and R. J. O. Davies, "Sleep - 6: obstructive sleep apnoea/hypopnoea syndrome and hypertension,” Thorax, vol. 59, no. 12, pp. 1089-1094, 2004.

[7] J. D. L. Lattimore, D. S. Celermajer, and I. Wilcox, "Obstructive sleep apnea and cardiovascular disease," Journal of the American College of Cardiology, vol. 41, no. 9, pp. 1429-1437, 2003.

[8] Y. Peker, H. Kraiczi, J. Hedner, S. Löth, A. Johansson, and M. Bende, "An independent association between obstructive sleep apnoea and coronary artery disease," European Respiratory Journal, vol. 14, no. 1, pp. 179-184, 1999.

[9] H. Yaggi and V. Mohsenin, "Obstructive sleep apnoea and stroke," The Lancet Neurology, vol. 3, no. 6, pp. 333-342, 2004.

[10] E. Shahar, C. W. Whitney, S. Redline et al., "Sleep-disordered breathing and cardiovascular disease: cross-sectional results of the sleep heart health study," American Journal of Respiratory and Critical Care Medicine, vol. 163, no. 1, pp. 19-25, 2001.

[11] A. Adlakha and J. W. Shepard Jr., "Cardiac arrhythmias during normal sleep and in obstructive sleep apnea syndrome," Sleep Medicine Reviews, vol. 2, no. 1, pp. 45-60, 1998.

[12] A. Svatikova, R. Wolk, A. S. Gami, M. Pohanka, and V. K. Somers, "Interactions between obstructive sleep apnea and the metabolic syndrome," Current Diabetes Reports, vol. 5, no. 1, pp. 53-58, 2005.

[13] N. Meslier, F. Gagnadoux, P. Giraud et al., "Impaired glucoseinsulin metabolism in males with obstructive sleep apnoea syndrome," European Respiratory Journal, vol. 22, no. 1, pp. 156-160, 2003.

[14] T. Young, P. E. Peppard, and D. J. Gottlieb, "Epidemiology of obstructive sleep apnea: a population health perspective," 
American Journal of Respiratory and Critical Care Medicine, vol. 165, no. 9, pp. 1217-1239, 2002.

[15] T. Young, J. Skatrud, and P. E. Peppard, "Risk Factors for Obstructive Sleep Apnea in Adults," Journal of the American Medical Association, vol. 291, no. 16, pp. 2013-2016, 2004.

[16] T. Young, P. E. Peppard, and S. Taheri, "Excess weight and sleep-disordered breathing," Journal of Applied Physiology, vol. 99, no. 4, pp. 1592-1599, 2005.

[17] K. Sutherland, R. W. W. Lee, C. L. Phillips et al., "Effect of weight loss on upper airway size and facial fat in men with obstructive sleep apnoea," Thorax, vol. 66, no. 9, pp. 797-803, 2011.

[18] J. Durán et al., "Obstructive sleep apnea-hypopnea and related clinical features in a population-based sample of subjects aged 30 to 70 yr," American Journal of Respiratory and Critical Care Medicine, vol. 163, no. 3, pp. 685-689, 2001.

[19] O. Resta, M. P. Foschino-Barbaro, G. Legari et al., "Sleeprelated breathing disorders, loud snoring and excessive daytime sleepiness in obese subjects," International Journal of Obesity, vol. 25, no. 5, pp. 669-675, 2001.

[20] M. Valencia-Flores, A. Orea, V. A. Castaño et al., "Prevalence of sleep apnea and electrocardiographic disturbances in morbidly obese patients," Obesity Research, vol. 8, no. 3, pp. 262-269, 2000.

[21] D. M. Hiestand, P. Britz, M. Goldman, and B. Phillips, "Prevalence of symptoms and risk of sleep apnea in the US population: results from the National Sleep Foundation Sleep in America 2005 Poll," Chest, vol. 130, no. 3, pp. 780-786, 2006.

[22] T. Young, E. Shahar, F. J. Nieto et al., "Predictors of sleepdisordered breathing in community-dwelling adults: the Sleep Heart Health Study," Archives of Internal Medicine, vol. 162, no. 8, pp. 893-900, 2002.

[23] P. E. Peppard, T. Young, M. Palta, J. Dempsey, and J. Skatrud, "Longitudinal study of moderate weight change and sleep-disordered breathing," Journal of the American Medical Association, vol. 284, no. 23, pp. 3015-3021, 2000.

[24] A. B. Newman, G. Foster, R. Givelber, F. J. Nieto, S. Redline, and T. Young, "Progression and regression of sleep-disordered breathing with changes in weight: the Sleep Heart Health Study," Archives of Internal Medicine, vol. 165, no. 20, pp. 2408-2413, 2005.

[25] P. V. Tishler, E. K. Larkin, M. D. Schluchter, and S. Redline, "Incidence of sleep-disordered breathing in an urban adult population: the relative importance of risk factors in the development of sleep-disordered breathing," Journal of the American Medical Association, vol. 289, no. 17, pp. 2230-2237, 2003.

[26] J. R. Stradling and J. H. Crosby, "Predictors and prevalence of obstructive sleep apnoea and snoring in 1001 middle aged men," Thorax, vol. 46, no. 2, pp. 85-90, 1991.

[27] L. Ferini-Strambi, M. Zucconi, S. Palazzi et al., "Snoring and nocturnal oxygen desaturations in an Italian middle-aged male population: epidemiologic study with an ambulatory device," Chest, vol. 105, no. 6, pp. 1759-1764, 1994.

[28] R. J. O. Davies, N. J. Ali, and J. R. Stradling, "Neck circumference and other clinical features in the diagnosis of the obstructive sleep apnoea syndrome," Thorax, vol. 47, no. 2, pp. 101-105, 1992.

[29] R. Grunstein et al., "Snoring and sleep apnoea in men: association with central obesity and hypertension," International Journal of Obesity, vol. 17, no. 9, pp. 533-540, 1993.

[30] A. N. Vgontzas, "Does obesity play a major role in the pathogenesis of sleep apnoea and its associated manifestations via inflammation, visceral adiposity, and insulin resistance?" Archives of Physiology and Biochemistry, vol. 114, no. 4, pp. 211-223, 2008.

[31] E. Shinohara, S. Kihara, S. Yamashita et al., "Visceral fat accumulation as an important risk factor for obstructive sleep apnoea syndrome in obese subjects," Journal of Internal Medicine, vol. 241, no. 1, pp. 11-18, 1997.

[32] K. E. Shelton, H. Woodson, S. Gay, and P. M. Suratt, "Pharyngeal fat in obstructive sleep apnea," American Review of Respiratory Disease, vol. 148, no. 2, pp. 462-466, 1993.

[33] R. J. Schwab, M. Pasirstein, R. Pierson et al., "Identification of upper airway anatomic risk factors for obstructive sleep apnea with volumetric magnetic resonance imaging," American Journal of Respiratory and Critical Care Medicine, vol. 168, no. 5, pp. 522-530, 2003.

[34] S. P. Patil, H. Schneider, A. R. Schwartz, and P. L. Smith, "Adult obstructive sleep apnea: pathophysiology and diagnosis," Chest, vol. 132, no. 1, pp. 325-337, 2007.

[35] A. R. Schwartz, S. P. Patil, A. M. Laffan, V. Polotsky, H. Schneider, and P. L. Smith, "Obesity and obstructive sleep apnea: pathogenic mechanisms and therapeutic approaches," Proceedings of the American Thoracic Society, vol. 5, no. 2, pp. 185-192, 2008.

[36] T. J. T. Sutherland, J. O. Cowan, S. Young et al., "The association between obesity and asthma: interactions between systemic and airway inflammation," American Journal of Respiratory and Critical Care Medicine, vol. 178, no. 5, pp. 469475, 2008.

[37] K. Spiegel, E. Tasali, P. Penev, and E. Van Cauter, "Brief communication: sleep curtailment in healthy young men is associated with decreased leptin levels, elevated ghrelin levels, and increased hunger and appetite," Annals of Internal Medicine, vol. 141, no. 11, pp. 846-850, 2004.

[38] A. Romero-Corral, S. M. Caples, F. Lopez-Jimenez, and V. K. Somers, "Interactions between obesity and obstructive sleep apnea: implications for treatment," Chest, vol. 137, no. 3, pp. 711-719, 2010.

[39] P. M. Suratt, R. F. McTier, L. J. Findley, S. L. Pohl, and S. C. Wilhoit, "Effect of very-low-calorie diets with weight loss on obstructive sleep apnea," American Journal of Clinical Nutrition, vol. 56, no. 1, supplement, pp. 182S-184S, 1992.

[40] M. Kansanen, E. Vanninen, A. Tuunainen et al., "The effect of a very low-calorie diet-induced weight loss on the severity of obstructive sleep apnoea and autonomic nervous function in obese patients with obstructive sleep apnoea syndrome," Clinical Physiology, vol. 18, no. 4, pp. 377-385, 1998.

[41] K. Johansson, M. Neovius, Y. T. Lagerros et al., "Effect of a very low energy diet on moderate and severe obstructive sleep apnoea in obese men: a randomised controlled trial," British Medical Journal, vol. 339, article b4609, 2009.

[42] K. Johansson, E. Hemmingsson, R. Harlid et al., "Longer term effects of very low energy diet on obstructive sleep apnoea in cohort derived from randomised controlled trial: prospective observational follow-up study," British Medical Journal, vol. 342, no. 7809, article d3017, 2011.

[43] B. Lam, K. Sam, W. Y. W. Mok et al., "Randomised study of three non-surgical treatments in mild to moderate obstructive sleep apnoea," Thorax, vol. 62, no. 4, pp. 354-359, 2007.

[44] T. Kemppainen, P. Ruoppi, J. Seppä et al., "Effect of weight reduction on rhinometric measurements in overweight patients with obstructive sleep apnea," American Journal of Rhinology, vol. 22, no. 4, pp. 410-415, 2008.

[45] M. Barnes, U. R. Goldsworthy, B. A. Cary, and C. J. Hill, "A diet and exercise program to improve clinical outcomes in patients 
with obstructive sleep apnea-a feasibility study," Journal of Clinical Sleep Medicine, vol. 5, no. 5, pp. 409-415, 2009.

[46] H. P. I. Tuomilehto, J. M. Seppä, M. M. Partinen et al., "Lifestyle intervention with weight reduction: first-line treatment in mild obstructive sleep apnea," American Journal of Respiratory and Critical Care Medicine, vol. 179, no. 4, pp. 320327, 2009.

[47] P. Nerfeldt, B. Y. Nilsson, L. Mayor, J. Uddén, and D. Friberg, "A two-year weight reduction program in obese sleep apnea patients," Journal of Clinical Sleep Medicine, vol. 6, no. 5, pp. 479-486, 2010.

[48] S. Kajaste, P. E. Brander, T. Telakivi, M. Partinen, and P. Mustajoki, "A cognitive-behavioral weight reduction program in the treatment of obstructive sleep apnea syndrome with or without initial nasal CPAP: a randomized study," Sleep Medicine, vol. 5, no. 2, pp. 125-131, 2004.

[49] J. F. Norman, S. G. Von Essen, R. H. Fuchs, and M. McElligott, "Exercise training effect on obstructive sleep apnea syndrome," Sleep Research Online, vol. 3, no. 3, pp. 121-129, 2000.

[50] G. Sampol, X. Muñoz, M. T. Sagalés et al., "Long-term efficacy of dietary weight loss in sleep apnoea/hypopnoea syndrome," European Respiratory Journal, vol. 12, no. 5, pp. 1156-1159, 1998.

[51] S. S. Smith, G. Doyle, T. Pascoe, J. A. Douglas, and G. Jorgensen, "Intention to exercise in patients with obstructive sleep apnea," Journal of Clinical Sleep Medicine, vol. 3, no. 7, pp. 689-694, 2007.

[52] M. J. Stock, "Sibutramine: a review of the pharmacology of a novel anti-obesity agent," International Journal of Obesity, vol. 21, supplement 1, pp. S25-S29, 1997.

[53] D. Martinez and B. R. Basile, "Sibutramine does not worsen sleep apnea syndrome: a randomized double-blind placebocontrolled study," Sleep Medicine, vol. 6, no. 5, pp. 467-470, 2005.

[54] B. J. Yee, C. L. Phillips, D. Banerjee, I. Caterson, J. A. Hedner, and R. R. Grunstein, "The effect of sibutramineassisted weight loss in men with obstructive sleep apnoea," International Journal of Obesity, vol. 31, no. 1, pp. 161-168, 2007.

[55] C. L. Phillips, B. J. Yee, M. I. Trenell et al., "Changes in regional adiposity and cardio-metabolic function following a weight loss program with sibutramine in obese men with obstructive sleep apnea," Journal of Clinical Sleep Medicine, vol. 5, no. 5, pp. 416-421, 2009.

[56] A. Ferland, P. Poirier, and F. Sériès, "Sibutramine versus continuous positive airway pressure in obese obstructive sleep apnoea patients," European Respiratory Journal, vol. 34, no. 3, pp. 694-701, 2009.

[57] National Collaborating Centre for Primary Care and the Centre for Public Health Excellence at the National Institute for Health and Clinical Excellence, "NICE Clinical Guideline 432006 Obesity guidance on the prevention, identification, assessment and management of overweight and obesity in adults and children," http://www.nice.org.uk/nicemedia/live/ 11000/30365/30365.pdf.

[58] G. de Simone and G. D’Addeo, "Sibutramine: balancing weight loss benefit and possible cardiovascular risk," Nutrition, Metabolism and Cardiovascular Diseases, vol. 18, no. 5, pp. 337-341, 2008.

[59] A. Ballinger, "Orlistat in the treatment of obesity," Expert Opinion on Pharmacotherapy, vol. 1, no. 4, pp. 841-847, 2000.

[60] S. J. Monkhouse, J. D. Morgan, S. E. Bates, and S. A. Norton, "An overview of the management of morbid obesity,"
Postgraduate Medical Journal, vol. 85, no. 1010, pp. 678-681, 2009.

[61] H. Ashrafian, M. Bueter, K. Ahmed et al., "Metabolic surgery: an evolution through bariatric animal models," Obesity Reviews, vol. 11, no. 12, pp. 907-920, 2010.

[62] M. Kalra and T. Inge, "Effect of bariatric surgery on obstructive sleep apnoea in adolescents," Paediatric Respiratory Reviews, vol. 7, no. 4, pp. 260-267, 2006.

[63] A. D. Rao, H. T. Beng, G. Ramalingam, and A. G. H. Poh, "Obstructive Sleep Apnoea (OSA) patterns in bariatric surgical practice and response of OSA to weight loss after laparoscopic adjustable gastric banding (LAGB)," Annals of the Academy of Medicine Singapore, vol. 38, no. 7, pp. 587-593, 2009.

[64] R. R. Grunstein, K. Stenlöf, J. A. Hedner, M. Peltonen, K. Karason, and L. Sjöström, "Two year reduction in sleep apnea symptoms and associated diabetes incidence after weight loss in severe obesity," Sleep, vol. 30, no. 6, pp. 703-710, 2007.

[65] C. Behrens, B. Q. Tang, and B. J. Amson, "Early results of a Canadian laparoscopic sleeve gastrectomy experience," Canadian Journal of Surgery, vol. 54, no. 2, pp. 138-143, 2011.

[66] M. Kalra, T. Inge, V. Garcia et al., "Obstructive sleep apnea in extremely overweight adolescents undergoing bariatric surgery," Obesity Research, vol. 13, no. 7, pp. 1175-1179, 2005.

[67] M. Valencia-Flores, A. Orea, M. Herrera et al., "Effect of bariatric surgery on obstructive sleep apnea and hypopnea syndrome, electrocardiogram, and pulmonary arterial pressure," Obesity Surgery, vol. 14, no. 6, pp. 755-762, 2004.

[68] J. J. Omana, S. Q. Nguyen, D. Herron, and S. Kini, "Comparison of comorbidity resolution and improvement between laparoscopic sleeve gastrectomy and laparoscopic adjustable gastric banding," Surgical Endoscopy and Other Interventional Techniques, vol. 24, no. 10, pp. 2513-2517, 2010.

[69] K. L. Haines, L. G. Nelson, R. Gonzalez et al., "Objective evidence that bariatric surgery improves obesity-related obstructive sleep apnea," Surgery, vol. 141, no. 3, pp. 354-358, 2007.

[70] D. A. Lankford, C. D. Proctor, and R. Richard, "Continuous positive airway pressure (CPAP) changes in bariatric surgery patients undergoing rapid weight loss," Obesity Surgery, vol. 15, no. 3, pp. 336-341, 2005.

[71] S. A. Guardiano, J. A. Scott, J. C. Ware, and S. A. Schechner, "The long-term results of gastric bypass on indexes of sleep apnea," Chest, vol. 124, no. 4, pp. 1615-1619, 2003.

[72] J. Peiser, P. Lavie, A. Ovnat, and I. Charuzi, "Sleep apnea syndrome in the morbidly obese as an indication for weight reduction surgery," Annals of Surgery, vol. 199, no. 1, pp. 112115, 1984.

[73] C. J. Lettieri, A. H. Eliasson, and D. L. Greenburg, "Persistence of obstructive sleep apnea after surgical weight loss," Journal of Clinical Sleep Medicine, vol. 4, no. 4, pp. 333-338, 2008.

[74] S. Rasheid, M. Banasiak, S. F. Gallagher et al., "Gastric bypass is an effective treatment for obstructive sleep apnea in patients with clinically significant obesity," Obesity Surgery, vol. 13, no. 1, pp. 58-61, 2003.

[75] J. B. Dixon, L. M. Schachter, and P. E. O’Brien, "Polysomnography before and after weight loss in obese patients with severe sleep apnea," International Journal of Obesity, vol. 29, no. 9, pp. 1048-1054, 2005.

[76] G. Pillar, R. Peled, and P. Lavie, "Recurrence of sleep apnea without concomitant weight increase 7.5 years after weight reduction surgery," Chest, vol. 106, no. 6, pp. 1702-1704, 1994.

[77] I. Charuzi, P. Lavie, J. Peiser, and R. Peled, "Bariatric surgery in morbidly obese sleep-apnea patients: short- and long-term 
follow-up," American Journal of Clinical Nutrition, vol. 55, no. 2, supplement, pp. 594S-596S, 1992.

[78] L. G. Fritscher, S. Canani, C. C. Mottin et al., "Bariatric surgery in the treatment of obstructive sleep apnea in morbidly obese patients," Respiration, vol. 74, no. 6, pp. 647-652, 2007.

[79] C. Poitou, M. Coupaye, J. P. Laaban et al., "Serum amyloid A and obstructive sleep apnea syndrome before and after surgically-induced weight loss in morbidly obese subjects," Obesity Surgery, vol. 16, no. 11, pp. 1475-1481, 2006.

[80] L. Busetto, G. Enzi, E. M. Inelmen et al., "Obstructive sleep apnea syndrome in morbid obesity: effects of intragastric balloon," Chest, vol. 128, no. 2, pp. 618-623, 2005.

[81] C. Martí-Valeri, A. Sabaté, C. Masdevall, and A. Dalmau, "Improvement of associated respiratory problems in morbidly obese patients after open Roux-en-Y gastric bypass," Obesity Surgery, vol. 17, no. 8, pp. 1102-1110, 2007.

[82] I. Charuzi, A. Ovnat, and J. Peiser, "The effect of surgical weight reduction on sleep quality in obesity-related sleep apnea syndrome," Surgery, vol. 97, no. 5, pp. 535-538, 1985.

[83] J. B. Dixon, L. M. Schachter, and P. E. O'Brien, "Sleep disturbance and obesity: changes following surgically induced weight loss," Archives of Internal Medicine, vol. 161, no. 1, pp. 102-106, 2001.

[84] A. Dhabuwala, R. J. Cannan, and R. S. Stubbs, "Improvement in co-morbidities following weight loss from gastric bypass surgery," Obesity Surgery, vol. 10, no. 5, pp. 428-435, 2000.

[85] N. V. Christou, D. Look, and L. D. MacLean, "Weight gain after short- and long-limb gastric bypass in patients followed for longer than 10 years," Annals of Surgery, vol. 244, no. 5, pp. 734-740, 2006.

[86] C. W. Lee, J. J. Kelly, and W. Y. Wassef, "Complications of bariatric surgery," Current Opinion in Gastroenterology, vol. 23, no. 6, pp. 636-643, 2007.

[87] H. Buchwald, R. Estok, K. Fahrbach, D. Banel, and I. Sledge, "Trends in mortality in bariatric surgery: a systematic review and meta-analysis," Surgery, vol. 142, no. 4, pp. 621-635, 2007.

[88] T. L. Vasquez and K. Hoddinott, "A potential complication of bi-level positive airway pressure after gastric bypass surgery," Obesity Surgery, vol. 14, no. 2, pp. 282-284, 2004.

[89] P. M. Suratt, R. F. McTier, L. J. Findley, S. L. Pohl, and S. C. Wilhoit, "Changes in breathing and the pharynx after weight loss in obstructive sleep apnea," Chest, vol. 92, no. 4, pp. 631637, 1987.

[90] I. Rubinstein, N. Colapinto, L. E. Rotstein, I. G. Brown, and V. Hoffstein, "Improvement in upper airway function after weight loss in patients with obstructive sleep apnea," American Review of Respiratory Disease, vol. 138, no. 5, pp. 1192-1195, 1988.

[91] A. R. Schwartz, A. R. Gold, N. Schubert et al., "Effect of weight loss on upper airway collapsibility in obstructive sleep apnea," American Review of Respiratory Disease, vol. 144, no. 3, pp. 494-498, 1991.

[92] L. Largerstrand and S. Rossner, "Effects of weight loss on pulmonary function in obese men with obstructive sleep apnoea syndrome," Journal of Internal Medicine, vol. 234, no. 3, pp. 245-247, 1993.

[93] R. Pasquali, P. Celella, F. Cirignotta et al., "Treatment of obese patients with obstructive sleep apnea syndrome (OSAS): effect of weight loss and interference of otorhinolaryngoiatric pathology," International Journal of Obesity, vol. 14, no. 3, pp. 207-217, 1990.

[94] G. D. Foster, K. E. Borradaile, M. H. Sanders et al., "A randomized study on the effect of weight loss on obstructive sleep apnea among obese patients with type 2 diabetes: the sleep AHEAD study," Archives of Internal Medicine, vol. 169, no. 17, pp. 1619-1626, 2009. 


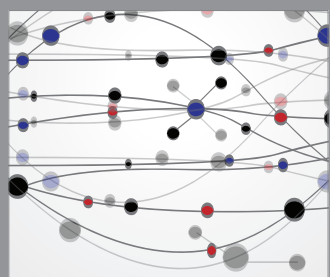

The Scientific World Journal
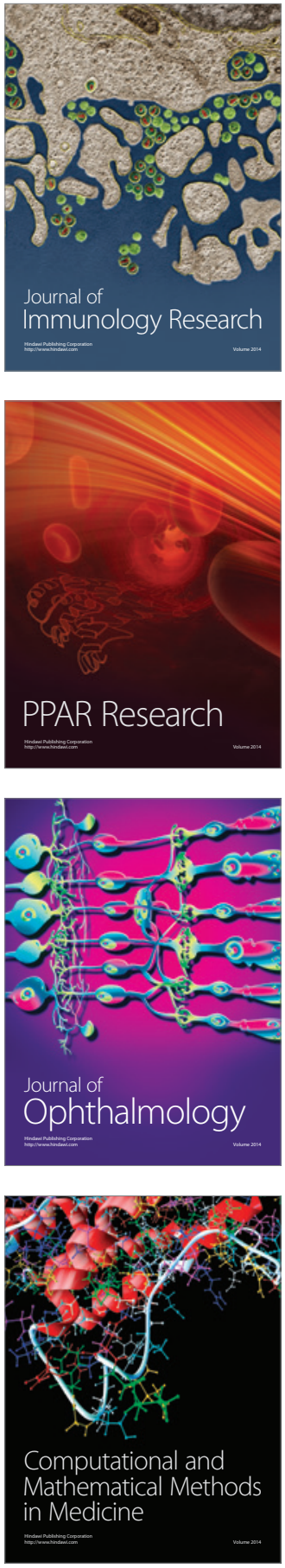

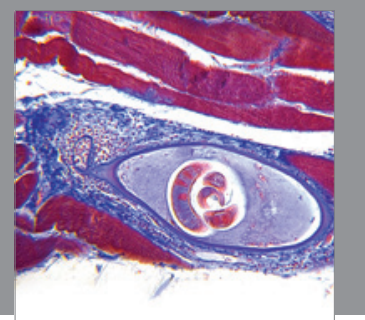

Gastroenterology

Research and Practice
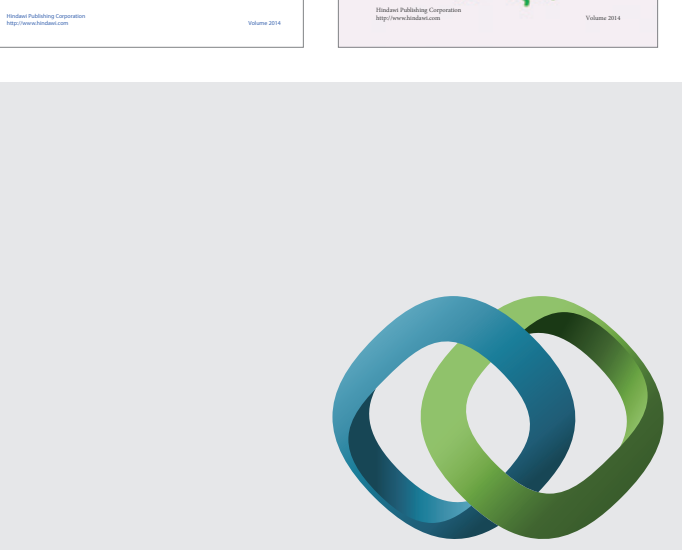

\section{Hindawi}

Submit your manuscripts at

http://www.hindawi.com
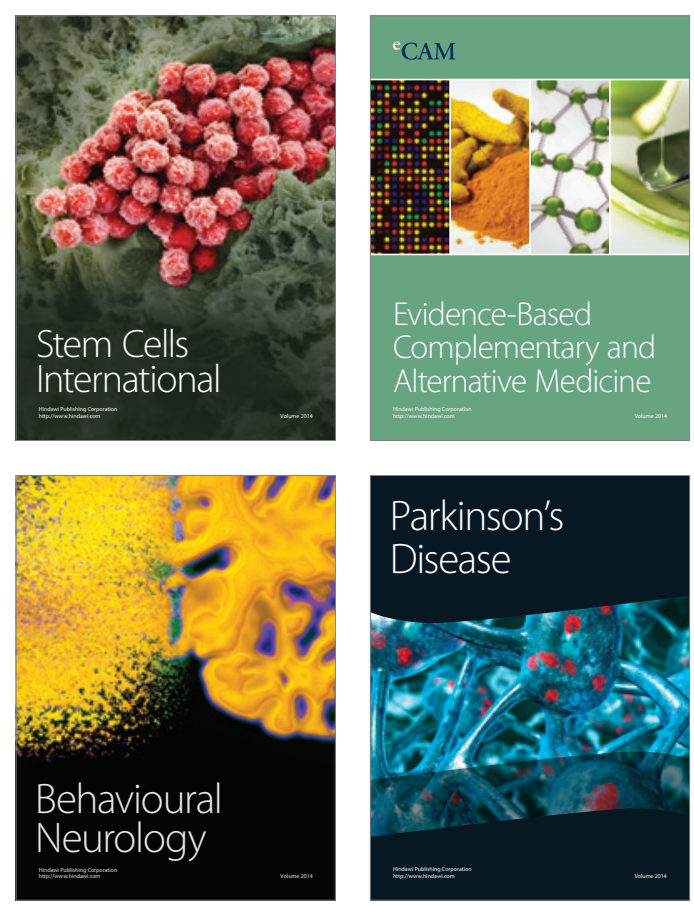

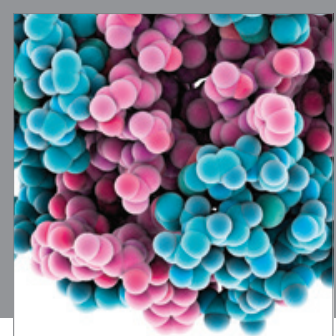

Journal of
Diabetes Research

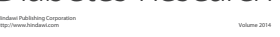

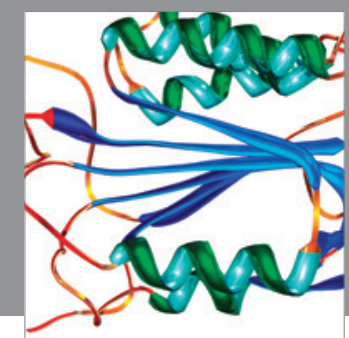

Disease Markers
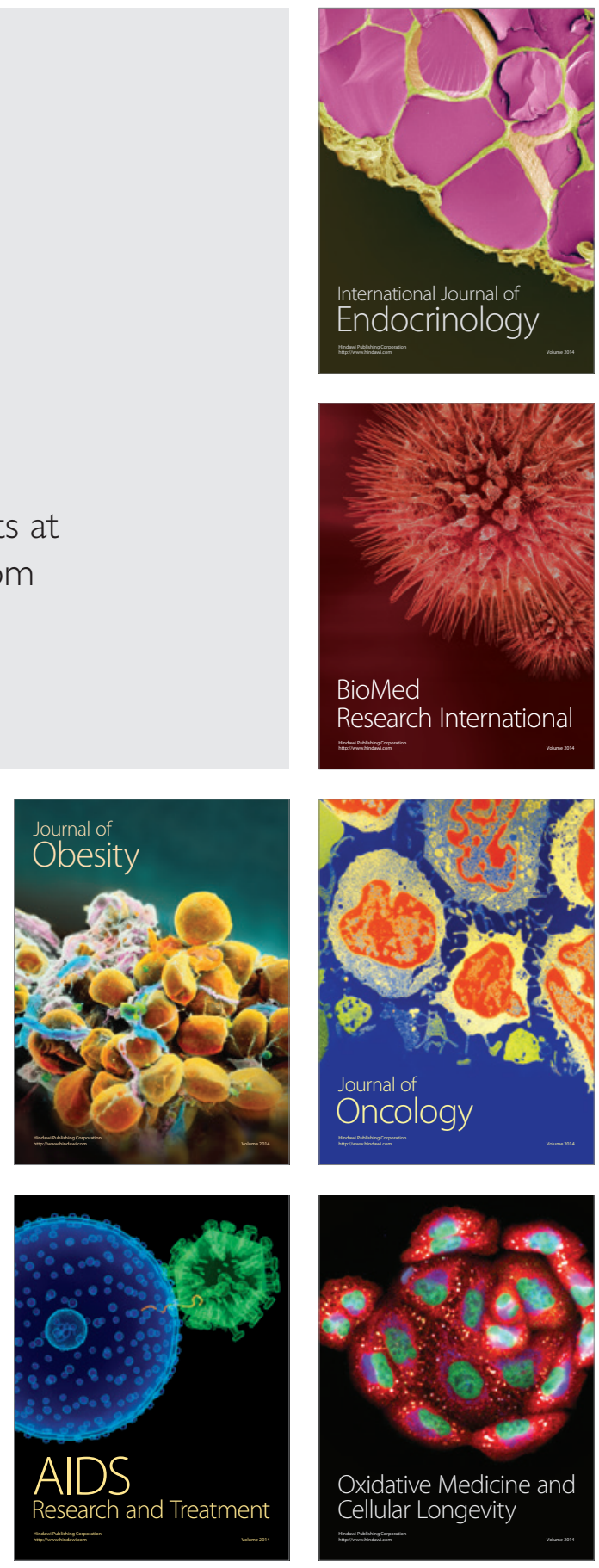